\title{
Artificial Neural Network Based Economic Generation Scheduling in Nigeria Power Network
}

\author{
Omorogiuwa Eseosa, Onohaebi S. O \\ Department of Elect-Elect Engineering, Faculty of Engineering, University of Port Harcourt, Nigeria \\ Department of Elect-Elect Engineering, Faculty of Engineering, University of Benin, Nigeria
}

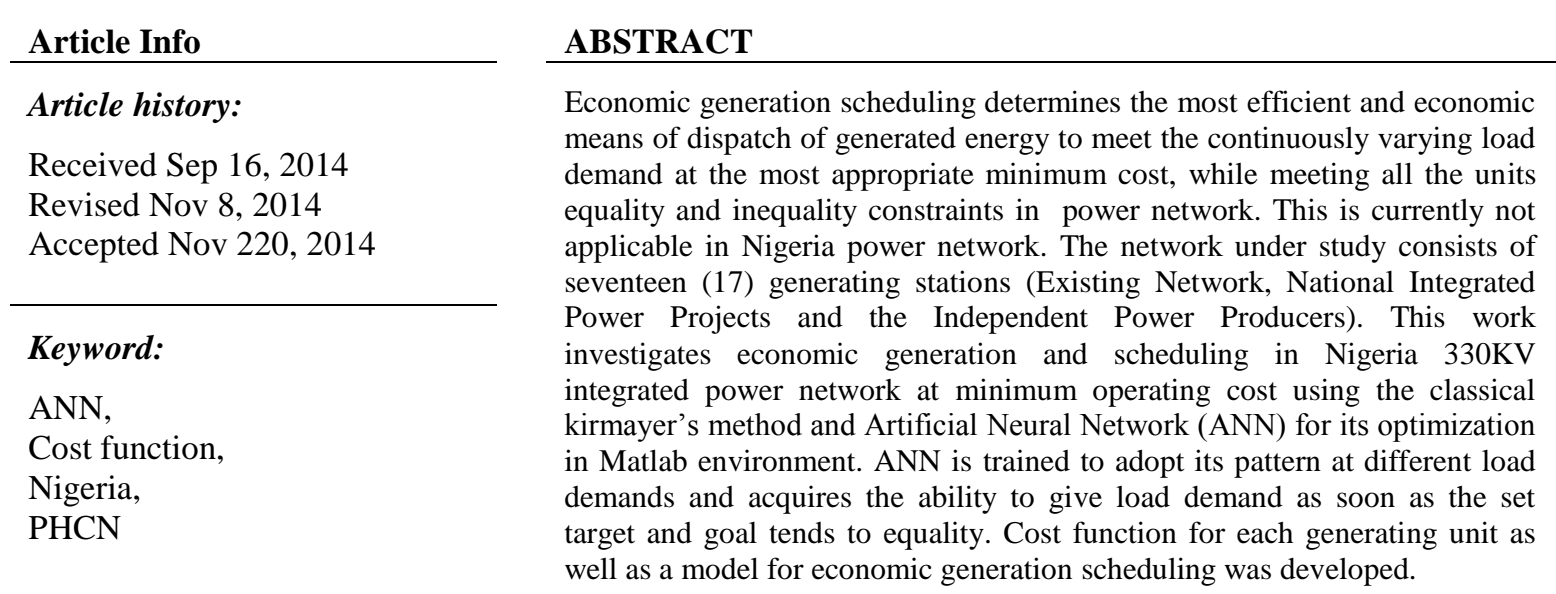

Copyright () 2014 Institute of Advanced Engineering and Science. All rights reserved.

\section{Corresponding Author:}

Omorogiuwa Eseosa,

Department of Elect-Elect Engineering,

Faculty of Engineering, University of Port Harcourt,

Rivers State, Nigeria.

Email: oomorogiuwa@yahoo.com

\section{INTRODUCTION}

Economic generation scheduling involves optimization of certain equality and inequality constraints in power network, while satisfying load demand at minimum operating cost. It determines the most efficient, low-cost and reliable operation of power system by dispatching the available electricity generation resources to supply load to the system [1]. Generally, generation scheduling has become necessary because of rapid increase of energy requirements.

Researchers reviewed economic load dispatch and generation scheduling and applied it to power network [1]-[5]. Considering the conventional approaches of schedule [6]-[10] and the use of intelligent methods for optimal scheduling such as Simulated Annealing (SA), Artificial Neural Network (ANN), Genetic Algorithm (GA), [11]-[17], it was found that accurate results were obtained even in very large and complex power networks compared to the conventional methods. Intelligent methods are computer-based problem solving systems which are computational models of evolutionary processes as key elements in their design and implementation [18]. It is un-economical to operate all available units in generating stations during peak and off peak period, hence the problem of unit commitment of each generator in the network. Unit commitment problem is solved by ensuring that there is a plan of units to be selected from generating facilities to meet predicted demand in a reliable and economic manner [19]. In solving this problem, ANN was used to generate pre-scheduling by adjusting their output according to priority of fuel cost per unit output [20], [21]. This work aims at using ANN based optimization technique for economic generation and scheduling in Nigeria $330 \mathrm{kV}$ power network and minimize overall cost of generation and power losses. It 
also involves modelling the network such that it can easily be adjusted to suit daily requirement and changes such as addition and removal of generating units.

\section{NIGERIA POWER NETWORK}

In an attempt to meet the increasing power demand, the country's electricity industry is undergoing changes in terms of building more generating stations, transmission lines and distribution lines/stations through National Independent Power Projects (NIPP) and Independent Power producers (IPP). NIPP and IPP have increased the numbers of generating stations from nine (9) to seventeen (17), transmission lines from thirty (30) to sixty-four (64) and buses from twenty-eight (28) to thirty-two (52) for the 330kV transmission grid. Presently, of the seventeen (17) active power generating stations, eight of these are owned by Federal Government (existing) with installed capacity of 6,256MW and 2,484MW is available. The remaining nine (9) are from both National Independent Power Project (NIPP) and the Independent Power Producers (IPP) with total designed capacity of $2,809 \mathrm{MW}$, of which $1,336.5 \mathrm{MW}$ is available [23].

Table 1 shows maximum and available generating capacities, their location and type of turbine.

Table 2 shows bus names.

Table 1. Nigeria Power Network Showing Their Maximum and Available Generating Capacities [23]

\begin{tabular}{|c|c|c|c|c|c|c|c|}
\hline $\mathrm{S} / \mathrm{N}$ & Power station & Location & $\begin{array}{c}\text { Turbine } \\
\text { type }\end{array}$ & Installed unit & Available unit & $\begin{array}{c}\text { Maximum Capacity } \\
\text { (MW) }\end{array}$ & $\begin{array}{c}\text { Available Capacity } \\
\text { (MW) }\end{array}$ \\
\hline 1 & Kainji & Niger & Hydro & 8 & 6 & 760 & 259 \\
\hline 2 & Jebba & Niger & Hydro & 6 & 5 & 540 & 402 \\
\hline 3 & Shiroro & Niger & Hydro & 4 & 3 & 600 & 408 \\
\hline 4 & Egbin & Lagos & Steam & 6 & 4 & 1320 & 900 \\
\hline 5 & Trans-Amadi & Rivers & Gas & 4 & 1 & 100 & 7.3 \\
\hline 5 & A.E.S (Egbin) & Lagos & Gas & 9 & 8 & 250 & 233.8 \\
\hline 6 & Sapele & Delta & Gas & 10 & 2 & 1020 & 170 \\
\hline 7 & Ibom & Akwa-Ibom & Gas & 4 & 1 & 155 & 25.3 \\
\hline 8 & Okpai & Delta & Gas & 3 & 2 & 900 & 223 \\
\hline 9 & Afam I-V & Rivers & Gas & 20 & 3 & 726 & 60 \\
\hline 10 & AfamVI(Shell) & Rivers & Gas & 6 & 5 & 650 & 550 \\
\hline 11 & Delta & Delta & Gas & 18 & 12 & 912 & 281 \\
\hline 12 & Geregu & Kogi & Gas & 3 & 3 & 414 & 120 \\
\hline 13 & Omoku & Rivers & Gas & 6 & 4 & 150 & 28 \\
\hline 14 & Omotosho & Ondo & Gas & 8 & 2 & 304 & 88.3 \\
\hline 15 & Okpai (Agip) & Delta & Gas & 6 & 6 & 480 & 480 \\
\hline 16 & $\begin{array}{l}\text { Olorunshogo } \\
\text { phase I }\end{array}$ & Ogun & Gas & 8 & 2 & 200 & 114.5 \\
\hline 17 & $\begin{array}{l}\text { Olorunshogo } \\
\text { phase II }\end{array}$ & Ogun & Gas & 8 & 2 & 200 & 200 \\
\hline \multicolumn{6}{|c|}{ Total Power } & 9545 & 4404 \\
\hline
\end{tabular}

Table 2. Bus Names [23]

\begin{tabular}{llllll}
\hline S/No & Buses & S/No & Buses & S/No & Buses \\
\hline 1 & Shiroro & 21 & New haven south & 41 & Yola \\
2 & Afam & 22 & Makurdi & 42 & Gwagwalada \\
3 & Ikot-Ekpene & 23 & B-kebbi & 43 & Sakete \\
4 & Port-Harcourt & 24 & Kainji & 44 & Ikot-Abasi \\
5 & Aiyede & 25 & Oshogbo & 45 & Jalingo \\
6 & Ikeja west & 26 & Onitsha & 46 & Kaduna \\
7 & Papalanto & 27 & Benin north & 47 & Jebba GS \\
8 & Aja & 28 & Omotosho & 48 & Kano \\
9 & Egbin PS & 29 & Eyaen & 49 & Katampe \\
10 & Ajaokuta & 30 & Calabar & 50 & Okpai \\
11 & Benin & 31 & Alagbon & 51 & Jebba \\
12 & Geregu & 32 & Damaturu & 52 & AES \\
13 & Lokoja & 33 & Gombe & & \\
14 & Akangba & 34 & Maiduguri & & \\
15 & Sapele & 35 & Egbema & & \\
16 & Aladja & 36 & Omoku & & \\
17 & Delta PS & 37 & Owerri & & \\
18 & Alaoji & 38 & Erunkan & & \\
19 & Aliade & 39 & Ganmo & & \\
20 & New haven & 40 & Jos & & \\
\hline
\end{tabular}


Nigeria as a nation is yet to meet the increasing energy requirements fully because of its limited power systems for generation and transmission, so it is important not to waste the limited energy generated and this can be achieved effectively by optimal generation and scheduling.

\subsection{Economic Generation and Scheduling Methods}

In power systems engineering, economic generation and scheduling have been used to plan over a given time horizon in order to obtain the most economical schedule of committing and dispatching generating units. The essence is to meet forecasted demand levels and spinning reserve requirements while all the generating unit constraints are satisfied. For inter connected power systems which contain multiple areas and tie lines, capacity constraints are also needed to be considered in the multi-area ELD. The generating unit schedule that yields minimum total production cost which consists of the following cost: fuel, operating crew members, maintenance, starting up and shutting down of generating units, which is the optimal solution of economic generation and scheduling (EGS are considered. The cost of power generation is solely dependent on the type of fuel used, the energy requirement of consumers and on power losses experienced in the power system. The ELD problem minimizes the total cost of generation while honoring the operational constraints of the available generation resources. EGS utilizes the use of every power generated thereby saving cost, losses and enabling an effective power plant. It will help countries like Nigeria struggling with the high demand of electricity to avoid wastage of its limited power generated.

Economic generation and scheduling (EGS) involves solution of two different problems. These are the unit commitment (UC) and the on-line economic dispatch (EP). Unit Commitment (UC) or pre-dispatch problem involves optimal selection of available generating sources, to operate and meet the expected load demand at minimum cost for a specified period of time. The on-line economic load dispatch is required to distribute load among generating units to minimize total cost of supplying the minute to minute requirements of the system and expected losses. Various methods have been used to tackle EGS. Mathematical formulations include conventional methods like Exhaustive Enumeration, Priority List, Lagrangian Relaxation, Sequential Method, Mixed Integer Programming, Decommitment Method, Dynamic Programming, Branch and Bound technique, Lambda Iterative Method, Gradient Method, Newton's Linear Programming. These methods are usually time consuming and usually prone to errors. With the advancement in technology, easier and more accurate methods have been adopted. These methods involve the use of computer programs. Though they may require special training and skills, they have proven to be the best in solving such problems. These methods include Genetic Algorithm (GA), Fuzzy Logic(FL), Tabu Search(TS), Artificial Neural Network(ANN), Particle Swarm Optimization(PSO) e.t.c. ANN has proven to be robust, easy to modify, not limited to a specific number of input and output, and it controls non-linear systems that would be difficult or impossible to model mathematically [13]-[14], [21]-[22].

\section{METHODOLOGY}

Classical Kirchmayer's method is used in this research work with ANN based optimization technique because of its robust, easy to adjust and its inability to be limited which are its advantages. The achieving the set objective, the following procedures is adopted for the work:

1. Define the control objectives, criteria and constraints.

2. Determine the number of generating stations to be studied and their capacity.

3. Create ANN and define the values of input/output terms.

4. Create the necessary pre and post processing ANN routines.

5. Set up and test the $330 \mathrm{KV}$ Network using the load flow results obtained from Power Word Simulator environment.

6. Evaluate the results.

\subsection{Mathematical Modeling of Economic Load Dispatch (ELD) Problem}

Mathematically, the conventional ELD can be represented as:

$$
\begin{aligned}
& \min F=\quad \sum_{i=1}^{N} 1 F_{i}\left(P_{i}\right) \\
& \left.F_{i}\left(P_{i}\right)=\quad a_{i}+\left(b_{i} P_{i}\right)+c_{i} P_{i}^{2}\right) \\
& \text { With } \mathrm{P}_{\mathrm{i} \min } \leq \mathrm{P}_{\mathrm{i}} \leq \mathrm{P}_{\text {imax }}
\end{aligned}
$$

Transmission loss is given as: 
$\mathrm{P}_{\mathrm{i}}=\mathrm{P}_{\mathrm{j}} \mathrm{B}_{\mathrm{j}}$

Subject to:

$$
\mathrm{P}_{\mathrm{D}}+\mathrm{P}_{\mathrm{L}}-\sum_{\mathrm{n}=1}^{\mathrm{N}} \mathrm{P}_{\mathrm{n}}=0
$$

Using the lagrangian multiplier $\lambda$, the auxiliary function is given by:

$$
\mathrm{A}=\mathrm{A}_{\mathrm{T}}+\lambda\left(\mathrm{P}_{\mathrm{D}}+\mathrm{P}_{\mathrm{L}}-\sum_{\mathrm{n}=1}^{\mathrm{N}} \mathrm{P}_{\mathrm{n}}\right)
$$

Partial differential of this expression when equated to zero gives the condition for the economic load dispatch, i.e.:

$$
\frac{\partial \mathrm{A}}{\partial \mathrm{P}_{\mathrm{n}}}=\frac{\partial A_{\mathrm{T}}}{\partial \mathrm{P}_{\mathrm{n}}}+\lambda\left[\frac{\partial \mathrm{P}_{\mathrm{L}}}{\partial \mathrm{P}_{\mathrm{n}}}-1\right]=0
$$

Or,

$$
\frac{\partial \mathrm{A}_{\mathrm{T}}}{\mathrm{dP}_{n}}+\lambda \frac{\partial \mathrm{P}_{\mathrm{L}}}{\partial \mathrm{P}_{\mathrm{n}}}=\lambda
$$

The term $\frac{\partial \mathrm{P}_{\mathrm{L}}}{\partial \mathrm{P}_{\mathrm{n}}}$ is known as the incremental transmission loss at a plant $\mathrm{n}$ and $\lambda$ is known as the incremental cost of the received power.

The Equation (4) and (5) are a set of $n$ equations with $(n+1)$ unknowns. These equations control both the incremental transmission losses and production cost.

To solve these equations, the loss formula is expressed in terms of generations and is approximately expressed as:

$$
\begin{aligned}
& P_{L}=\sum_{i=1}^{N} \sum_{i=1}^{N} 1 P_{i} P_{i j} P_{j}+\sum_{i=1}^{N} 1 B_{0 i} P_{i}+B B_{00} \\
& \text { With } \quad \mathrm{P}_{i, \min } \leq \mathrm{P}_{i} \leq \mathrm{P}_{i, \max }
\end{aligned}
$$

Where,

$F=$ is the system overall cost function;

$N=$ the number of generators in the system, $\mathrm{C}_{\mathrm{i}}, \mathrm{b}_{\mathrm{i}}$ and $\mathrm{a}_{\mathrm{i}}$ are cost constants which include the following;

$\mathrm{c}_{\mathrm{i}}=$ is a measure of losses in the system, $b_{i}$ is the fuel cost and $a_{i}$ is the salary/wages, interest and depreciation of the machines.

$P_{D}=$ the total power system demand; $P_{L}=$ the total system transmission losses

$\mathrm{P}_{\mathrm{i}}=$ the active power generation of generator number $I ; \mathrm{B}_{\mathrm{ij}}, \mathrm{B}_{0 \mathrm{i}}, \mathrm{B}_{00}=$ Transmission loss coefficients.

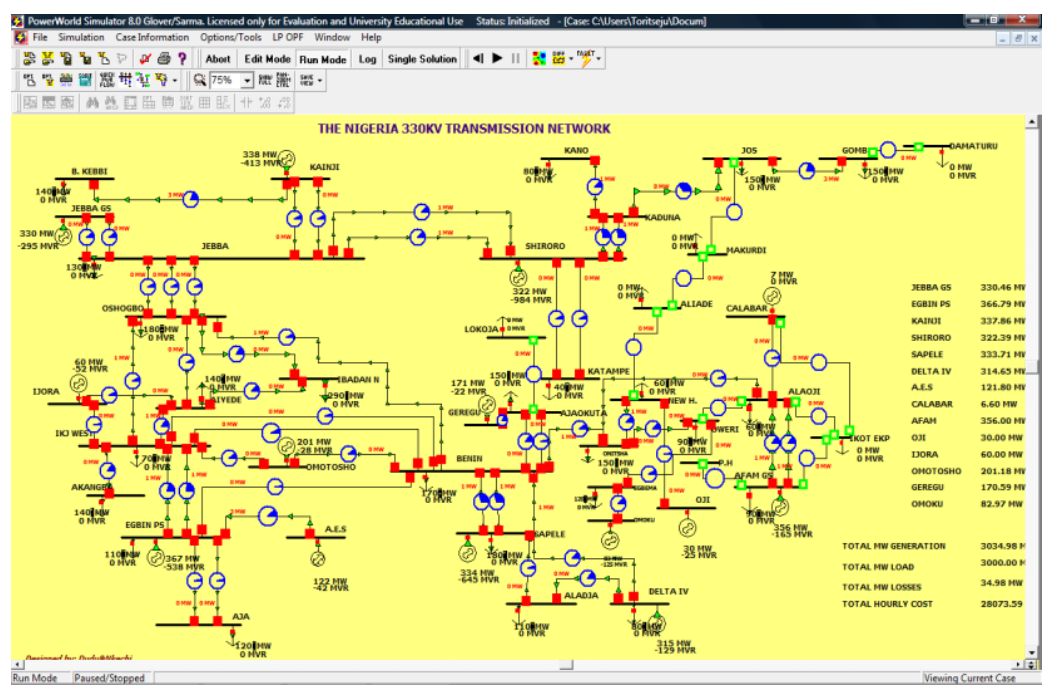

Figure 1. Modelling of Nigeria 330kV power network 
Figure 1 shows the modelling of Nigeria $330 \mathrm{kV}$ power network in power world simulator environment. This model is achieved by obtaining data such as transmission line parameters, bus data, load data, reactors sizes, transformers sizes and generators power limit (active and reactive). Table 3 shows the result obtained for the various this give the power flow and losses in the network as shown. The result obtained from this model is now used for the training of the network using artificial neural network.

\subsection{Training the Network Using ANN}

The algorithm to train the neural network is typed on the editor window of Matlab. This program calls up the neural network tool and analyses the total area load demand as the input to the neural network. The electric power generation of the seventeen power stations, are taken as the output of the neural network. For the purpose of training the neural network, data were obtained from the simulated results from Power World Simulator at fourteen different total area load demand to ensure a fast learning rate and ability to produce correct output when fed with a different input. These data are shown in appendix A. After preparing adequate data for training and test of neural networks, now the important key is selecting the number of neurons in the hidden layer of the networks such that the exactness of network is maximum. For this reason, the neural network is trained with five neurons in the hidden layer and a neuron in the output layer. A number of 200 epochs is considered. The Tan-Sigmoid Transfer Function was used in the hidden layer while the Linear Transfer Function was used in the output layer. Also, the default Levenberg-Marquardt algorithm (trainlm) was adopted to achieve a better training speed.The figures of the Training Pattern of the Neural Network and the Linear Regression for the Generation Output (MW) of the trained system are obtained after the program has been run for analysis by clicking on the run icon. Figure 2 shows the training of the data obtained from PHCN. This gives a Regression (R). It measures the correlation between outputs and targets. An $\mathrm{R}$ value of 1 means a close relationship, 0 a random relationship. The next step then involves setting a goal so as to know when the training will end considering all the constraints. Figure 3 shows that the performance goal of the network was met after 61 epochs.

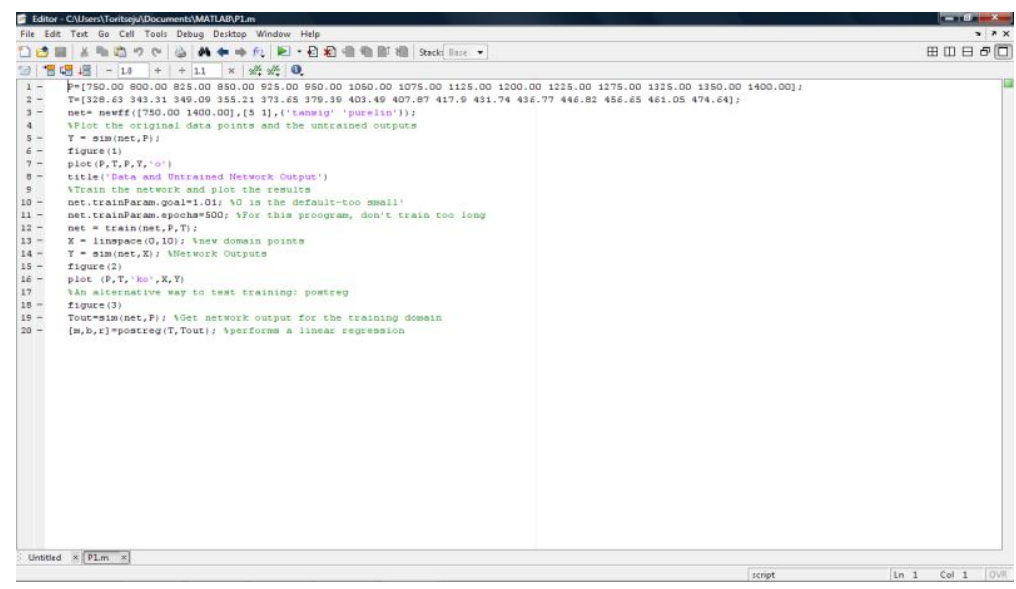

Figure 2. Training the data using artificial neural network

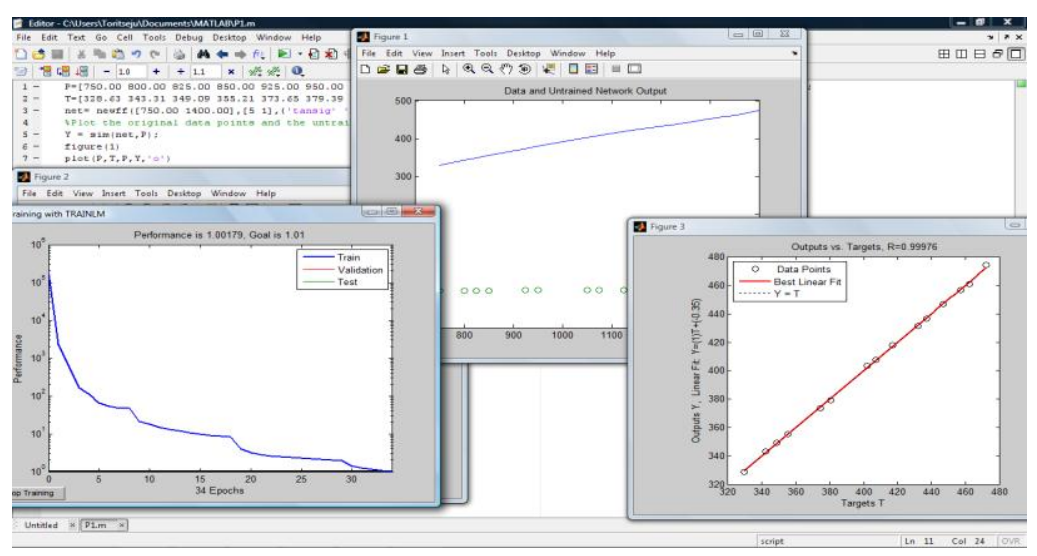

Figure 3. Performance goal of the network 
Tables 3 and 4 respectively showed the generation scheduling using power world simulator and then applying ANN for the power generation scheduling respectively. The generating stations are shown also for range of power between $1500 \mathrm{MW}$ and $6000 \mathrm{MW}$.

Table 3. Simulated Results of Nigeria 330kV Economic Generation Scheduling

\begin{tabular}{|c|c|c|c|c|c|c|c|c|c|}
\hline $\begin{array}{l}\text { TotalArea } \\
\text { (MW) }\end{array}$ & Load & $\begin{array}{l}\text { Jebba } \\
\text { (MW) }\end{array}$ & $\begin{array}{l}\text { Egbin } \\
(\mathrm{MW})\end{array}$ & $\begin{array}{l}\text { Kainji } \\
\text { (MW) }\end{array}$ & $\begin{array}{l}\text { Shiroro } \\
\text { (MW) }\end{array}$ & $\begin{array}{l}\text { Sapele } \\
\text { (MW) }\end{array}$ & $\begin{array}{l}\text { Delta } \\
\text { (MW) }\end{array}$ & IV & $\begin{array}{l}\text { A.E.S } \\
\text { (MW) }\end{array}$ \\
\hline 1500.00 & & 206.66 & 195.06 & 206.07 & 176.04 & 165.59 & 170.69 & & 44.70 \\
\hline 1750.00 & & 228.29 & 223.14 & 229.20 & 202.18 & 192.14 & 193.70 & & 57.63 \\
\hline 2000.00 & & 247.89 & 253.16 & 249.90 & 224.75 & 215.47 & 212.16 & & 71.30 \\
\hline 2250.00 & & 266.97 & 281.52 & 270.14 & 246.17 & 243.81 & 236.89 & & 84.09 \\
\hline 2500.00 & & 287.61 & 312.64 & 292.01 & 270.16 & 272.40 & 260.94 & & 97.97 \\
\hline 2700.00 & & 304.00 & 327.59 & 310.12 & 293.23 & 295.08 & 283.90 & & 104.60 \\
\hline 3000.00 & & 327.52 & 370.77 & 334.85 & 317.02 & 332.48 & 315.75 & & 123.52 \\
\hline 3700.00 & & 381.07 & 448.02 & 391.74 & 383.50 & 415.95 & 387.92 & & 156.69 \\
\hline 4000.00 & & 407.07 & 488.41 & 419.68 & 406.44 & 455.67 & 420.61 & & 173.67 \\
\hline 4250.00 & & 431.46 & 520.08 & 445.81 & 436.54 & 484.15 & 445.31 & & 186.84 \\
\hline 4750.00 & & 475.70 & 588.20 & 493.07 & 485.28 & 550.46 & 502.88 & & 214.66 \\
\hline 5500.00 & & 540.00 & 703.10 & 582.27 & 590.88 & 663.83 & 598.97 & & 260.08 \\
\hline 5750.00 & & 540.00 & 756.83 & 614.14 & 600.00 & 721.43 & 600.00 & & 270.00 \\
\hline 6000.00 & & 540.00 & 833.23 & 687.26 & 600.00 & 791.80 & 599.68 & & 270.00 \\
\hline
\end{tabular}

\begin{tabular}{ccccccc}
\hline Calabar (MW) & Afam $(\mathrm{MW})$ & Oji (MW) & Ijora $(\mathrm{MW})$ & Omotosho $(\mathrm{MW})$ & Geregu $(\mathrm{MW})$ & Omoku $(\mathrm{MW})$ \\
\hline 0.00 & 152.31 & 9.52 & 0.00 & 92.58 & 61.86 & 36.38 \\
0.00 & 180.80 & 15.29 & 13.32 & 110.15 & 79.74 & 42.74 \\
1.13 & 222.21 & 22.61 & 28.30 & 126.96 & 93.96 & 50.86 \\
6.60 & 250.12 & 28.42 & 43.33 & 144.83 & 111.59 & 57.27 \\
6.60 & 275.83 & 30.00 & 59.20 & 163.79 & 129.67 & 63.61 \\
6.60 & 320.22 & 30.00 & 60.00 & 176.30 & 145.06 & 73.77 \\
6.60 & 357.44 & 30.00 & 60.00 & 201.42 & 167.50 & 82.18 \\
6.60 & 503.97 & 30.00 & 60.00 & 253.06 & 223.68 & 100.00 \\
6.60 & 550.53 & 30.00 & 60.00 & 278.75 & 247.71 & 100.00 \\
6.60 & 590.77 & 30.00 & 60.00 & 298.20 & 265.85 & 100.00 \\
6.60 & 669.88 & 30.00 & 60.00 & 335.00 & 300.00 & 100.00 \\
6.60 & 813.60 & 30.00 & 60.00 & 335.00 & 300.00 & 100.00 \\
6.60 & 903.72 & 30.00 & 60.00 & 335.00 & 300.00 & 100.00 \\
6.60 & 958.86 & 30.00 & 60.00 & 335.00 & 300.00 & 100.00 \\
\hline
\end{tabular}

Table 4. ANN's Response to Simulated Generation Output for Ijora Power Station

\begin{tabular}{llll}
\hline Total Area Load(MW) & Simulated Gen. (MW) & ANN's Response (MW) & \% Error \\
\hline 1750.00 & 13.32 & 13.40 & 0.60 \\
2000.00 & 28.30 & 28.41 & 0.39 \\
2250.00 & 43.33 & 43.24 & 0.21 \\
2500.00 & 59.20 & 58.99 & 0.35 \\
2700.00 & 60.00 & 59.97 & 0.05 \\
3000.00 & 60.00 & 59.94 & 0.10 \\
4000.00 & 60.00 & 60.00 & 0.00 \\
4250.00 & 60.00 & 60.00 & 0.00 \\
5500.00 & 60.00 & 60.00 & 0.00 \\
6000.00 & 60.00 & 60.00 & 0.00 \\
\hline
\end{tabular}

For Calabar Power Station:

\begin{tabular}{llll}
\hline Total Area Load(MW) & Simulated Gen. (MW) & ANN's Response (MW) & \%Error \\
\hline 1750.00 & 0.00 & 0.00 & 0.00 \\
2000.00 & 1.13 & 1.10 & 2.65 \\
2250.00 & 6.60 & 6.61 & 0.15 \\
2500.00 & 6.60 & 6.60 & 0.00 \\
2700.00 & 6.60 & 6.00 & 9.11 \\
3000.00 & 6.60 & 5.99 & 9.24 \\
4000.00 & 6.60 & 5.98 & 9.39 \\
4250.00 & 6.60 & 6.61 & 0.15 \\
5500.00 & 6.60 & 6.60 & 0.00 \\
6000.00 & 6.60 & 6.60 & 0.00 \\
\hline
\end{tabular}


For Shiroro Power Station:

\begin{tabular}{llll}
\hline Total Area Load (MW) & Simulated Gen. (MW) & ANN's Response (MW) & \%Error \\
\hline 1750.00 & 202.18 & 201.85 & 0.16 \\
2000.00 & 224.75 & 225.02 & 0.12 \\
2250.00 & 246.17 & 247.26 & 0.44 \\
2500.00 & 270.16 & 267.98 & 0.81 \\
2700.00 & 293.23 & 295.26 & 0.69 \\
3000.00 & 317.02 & 316.22 & 0.25 \\
4000.00 & 406.44 & 405.67 & 0.19 \\
4250.00 & 436.54 & 435.73 & 0.19 \\
5500.00 & 590.88 & 590.16 & 0.12 \\
6000.00 & 600.00 & 600.22 & 0.04 \\
\hline
\end{tabular}

For Omoku Power Station:

\begin{tabular}{llll}
\hline Total Area Load(MW) & Simulated. Gen. (MW) & ANN's Response (MW) & \%Error \\
\hline 1750.00 & 42.74 & 42.72 & 0.05 \\
2000.00 & 50.86 & 50.87 & 0.02 \\
2250.00 & 57.27 & 57.30 & 0.05 \\
2500.00 & 63.61 & 63.63 & 0.03 \\
2700.00 & 73.77 & 73.77 & 0.00 \\
3000.00 & 82.18 & 82.20 & 0.02 \\
4000.00 & 100.00 & 100.00 & 0.00 \\
4250.00 & 100.00 & 100.03 & 0.03 \\
5500.00 & 100.00 & 100.04 & 0.04 \\
6000.00 & 100.00 & 100.04 & 0.04 \\
\hline
\end{tabular}

For Afam Power Station:

\begin{tabular}{llll}
\hline Total Area Load(MW) & Simulated Gen. (MW) & ANN's Response (MW) & \%Error \\
\hline 1750.00 & 180.80 & 180.56 & 0.13 \\
2000.00 & 222.21 & 222.10 & 0.05 \\
2250.00 & 250.12 & 249.11 & 0.40 \\
2500.00 & 275.83 & 275.46 & 0.13 \\
2700.00 & 320.22 & 321.51 & 0.40 \\
3000.00 & 357.44 & 356.98 & 0.13 \\
4000.00 & 550.53 & 551.45 & 0.17 \\
4250.00 & 591.16 & 0.07 \\
5500.00 & 590.77 & 812.71 & 0.11 \\
\hline
\end{tabular}

For Kainji Hydro Power Station:

\begin{tabular}{llll}
\hline Total Area Load (MW) & Simulated Gen. (MW) & ANN's Response (MW) & \%Error \\
\hline 1750.00 & 229.20 & 229.25 & 0.02 \\
2000.00 & 249.90 & 249.10 & 0.32 \\
2250.00 & 270.14 & 269.98 & 0.06 \\
2500.00 & 292.01 & 292.10 & 0.03 \\
2700.00 & 310.12 & 312.22 & 0.68 \\
3000.00 & 334.85 & 333.99 & 0.26 \\
4000.00 & 419.68 & 420.22 & 0.13 \\
4250.00 & 445.81 & 446.18 & 0.08 \\
5500.00 & 582.27 & 583.62 & 0.23 \\
6000.00 & 687.26 & 686.79 & 0.07 \\
\hline
\end{tabular}

For Orji Power Station:

\begin{tabular}{llll}
\hline Total Area Load (MW) & Simulated Gen. $(\mathrm{MW})$ & ANN's Response $(\mathrm{MW})$ & \% \\
\hline 1750.00 & 15.29 & 15.40 & 0.72 \\
2000.00 & 22.61 & 22.55 & 0.27 \\
2250.00 & 28.42 & 28.44 & 0.07 \\
2500.00 & 30.00 & 29.97 & 0.10 \\
2700.00 & 30.00 & 29.99 & 0.03 \\
3000.00 & 30.00 & 29.99 & 0.03 \\
4000.00 & 30.00 & 29.99 & 0.03 \\
4250.00 & 30.00 & 29.99 & 0.03 \\
5500.00 & 30.00 & 29.99 & 0.03 \\
6000.00 & 30.00 & 29.99 & 0.03 \\
\hline
\end{tabular}




\section{DISCUSSION}

In other to economically dispatch power generated, it must be as economical as possible. In large interconnected systems, it is humanly impossible to calculate and adjust each generation and hence the help of digital computer system is being used and the whole process is carried out automatically. The most economic generation scheduling of power in the Nigeria $330 \mathrm{KV}$ network is determined for each station as shown both in Table 3 and 4 respectively. The first stage is to model the Nigeria 330KV network in power world simulator environment in order to obtain the best schedule if a certain quantity of generation is required assume a range of (1500MW-6000MW) as shown in Table 3. The next stage is then to further optimize these generations scheduling using ANN approach and then make comparison between the simulated scheduling with and without optimization as shown in Table 4. In the course of this work, PWS (power system modelling software) is used to determine economic generation scheduling considering transmission losses of power plants very efficiently and accurately. Different generation scheduling values ranging from 1500MW-6000MW were used. This schedule ensures that the systems are always not stressed beyond their thermal limit and the losses of each power station and their constraints are put into consideration. A case of load schedule of 1500MW shows contribution of individual generators as economical as possible considering generating power within the acceptable loss range and power limits (active and reactive) .Take also an instance of the Nigeria power network generating 2500MW, for optimal scheduling, the various stations are required to generate various quantity of power as shown in table 3.0. However considering the same quantity of power generation using ANN approach, and then comparing the same result without the ANN, the results obtained is shown in table 4.0.Percentage errors were computed to show the best approach and it was found that adopting ANN for generation scheduling is best as its very economical.

\section{CONCLUSION/RECOMMENDATION}

Economic load dispatch in electric power sector is an important task, as it is required to distribute the load among the generating units actually paralleled with the system in such a manner as to minimise the cost of supplying the minute to minute requirement of the system which aids in profit-making. In a large interconnected system, it is humanly impossible to calculate and adjust each generation and hence the help of digital computer system is being used and the whole process is carried out automatically. Currently the practice of ELD is not obtainable in Nigeria. It is therefore recommended that the Nigeria government should adopt the approach of economically scheduling power generation.

\section{REFERENCES}

[1] Chowdhury B. H., et al., "A review of recent advances in economic dispatch," IEEE Trans Power Syst., 1990, Vol. 5, No. 4, pp. 1248-1257.

[2] Ross D. W., et al., "Dynamic economic dispatch of generation," IEEE Trans Power Appar Syst., 1980, Vol. 99, No. 6, pp. 2060-2068.

[3] Rabin A.J., et al., "A homogeneous linear programming algorithm for the security constrained economic dispatch problem,” IEEE Trans Power Syst., 2000, Vol. 15, No. 3, pp. 930-936.

[4] Lin C. E., et al., "Hierarchical economic dispatch for piecewise quadratic cost functions," IEEE Trans Power Appar Syst., 1984, Vol. 103, No. 6, pp. 1170-1175.

[5] Chen S. D., et al., "A direct Newton-Raphson economic emission dispatch,” Electr Power Energy Syst., 2003, Vol. 25, pp. 411-417.

[6] Wood A. J., et al.. "Power generation, operation and control," New York: John Wiley \& Sons. 1994.

[7] Liang Z. X., et al., "A zoom feature for a programming solution to economic dispatch including transmission losses," IEEE Trans Power Syst., 1992, Vol. 7, No. 3, pp. 544-550.

[8] Fan J. Y., et al., "Real-time economic dispatch with line flow and emission constraints using quadratic programming," IEEE Trans Power Syst., 1998, Vol. 13, No. 2, pp. 320-325.

[9] Chen C. L., et al., "Branch-and-bound scheduling for thermal generating units," IEEE Trans Energy Conver., 1993, Vol. 8, No. 2, pp. 184-189.

[10] Yang H. T., et al., "Incorporating a multi-criteria decision procedure into the combined dynamic programming/production simulation algorithm for generation expansion planning," IEEE Trans Power Syst., 1989, Vol. 4, No. 1, pp. 165-175.

[11] Sinha N., et al., "Evolutionary programming techniques for economic load dispatch," IEEE Trans Evol Comput., 2003, Vol. 7, No. 1, pp. 83-94.

[12] Roa-Sepulveda C. A., et al., "A solution to the optimal power flow using simulated annealing," Electr Power Energy Syst, 2003, Vol. 25, No. 1, pp. 47-57.

[13] Kumar J., et al., "Clamped state solution of artificial neural network for real-time economic dispatch," IEEE Trans Power Syst, 1995, Vol. 10, No. 2, pp. 925-931.

[14] Yalcinoz T., et al., "Neural network approach for solving economic dispatch problem with transmission capacity constraints," IEEE Trans Power Syst., 1998, Vol. 13, No. 2, pp. 307-313. 
[15] Michalewicz Z., et al., "Evolutionary algorithms for constrained parameter optimization problems," Evol Comput., 1996, Vol. 4, No. 1, pp. 1-32.

[16] Gaing Z. L., "Particle swarm optimization to solving the economic dispatch considering the generator constraints," IEEE Trans Power Syst., 2003, Vol. 18, No. 3, pp. 1187-1195.

[17] Park J. B., et al., "A particle swarm optimization for economic dispatch with non smooth cost function," IEEE Trans Power Syst., 2005, Vol. 20, No. 1, pp. 34-42.

[18] N. Rajkumar, et al., "A Review of Genetic Algorithms in Power Engineering," AI and Machine Consciousness, Proceedings of the $13^{\text {th }}$ Finnish, Artificial Intelligence Conference Step, 2008, pp. 15-32.

[19] R.Nayak, et al., "A Hybrid Neural Network and Simulated Annealing Approach to the Unit Commitment Problem".

[20] Nayak R., "Neural Network Approach to Unit Commitment Problem," M.E.-Dissertation, Dept of Electrical Eng., University of Roorkee, India, 1995.

[21] Ouyang Z., et al., "A Hybrid Artificial Neural Network-Dynamic Programming Approach to Unit Commitment," IEEE Transactions on PS, 1992, pp. 236-242.

[22] Sasaki H., et al., "A solution Method using Neural Network for the Generator Commitment Problem," Electrical Eng. in Japan, 1992, Vol. 112, pp. 55-61.

[23] E Omorogiuwa, et al., "Determination Of Bus Voltages, Power Losses And Flows In The Nigeria 330kv Integrated Power System," International Journal Of Advances In Engineering \& Technology, 2012, Vol. 4, No. 1, pp. 94-106. 